\title{
BUBBLE FORMATION FROM A VERTICALLY DOWNWARD FACING NOZZLE IN LIOUIDS AND MOLTEN METALS
}

\author{
HIDEKI TSUGE \\ Department of Applied Chemistry, Keio University, Yokohama 223 \\ PETER RÜDIN AND ROLAND KAMMEL \\ Institut für Metallhüttenkunde, Technische Universität Berlin, Berlin 1000 F.R.G.
}

\begin{abstract}
Key Words: Fluid Mechanics, Chemical Reactor, Bubble, Bubble Formation, Molten Metal, Downward
Nozzle, Wettability, High Temperature
\end{abstract}

\begin{abstract}
A two-stage bubble formation model is presented for constant-flow conditions to predict the size of bubbles formed at a single downward-facing nozzle submerged in liquids or liquid metals.

Agreement between results calculated by this model and experimental data for water was fairly good over a wide range of experimental conditions, but not good for copper melt. The reasons for this discrepancy are discussed.
\end{abstract}

\section{Introduction}

Gas dispersion in liquids has played an important role in many physical and chemical processes in bringing about efficient mass and heat transfer between gas and liquid phases. Bubbling phenomena in copper converting and steelmaking have also recently received much attention.

One common dispersion method is blowing the gas through nozzles or orifices submerged in liquids. Much research has been done on bubble formation from upward-facing nozzles or orifices in liquids and molten metals. ${ }^{4,9,13)}$ Some empirical equations and bubble formation models have been presented to predict the size of bubbles formed from upward nozzles and orifices in liquids and liquid metals, but little has been known about bubble formation from downward-facing nozzles. ${ }^{14)}$

The purpose of the present study is to propose a bubble formation model which predicts the bubble size when bubbles are formed at a submerged downward-facing nozzle in liquids and molten metals. To examine the validity of the proposed model, the calculated results were compared with experimental results for water and copper melt.

\section{Bubble Formation Model and Mathematical For- mulation}

Some theoretical and empirical equations have been presented for the size of bubbles formed at wetted upward nozzles in water and organic liquids ${ }^{2,5}$

Received December 2, 1985. Correspondence concerning this article should be addressed to $H$. Tsuge. P. Rüdin is now with SUVA, Luzern, Switzerland. and at nonwetted upward nozzles in molten metals. ${ }^{9)}$ On the other hand, few theoretical and empirical equations have been obtained for the size of bubbles formed at downward-facing nozzles in molten metals or in water or organic liquids. Wraith ${ }^{14)}$ proposed a one-stage model by considering the simple force balance between the buoyancy and inertial force under constant gas flow conditions, and obtained the following equation for the air-water system.

$$
d_{b}=0.821 Q_{g}^{0.4}
$$

Though Eq. (1) agrees well with his experimental results for large gas flow rate, the range of applicability of this model seems to be limited. Therefore, the following two-stage model is presented for better understanding of bubble formation for a wider range of gas flow rate.

The two-stage formation model of bubbles formed at a single vertically downward nozzle in liquids and liquid metals is based on the following assumptions.

(1) The flow rate of gas flowing into the bubble through a nozzle is constant during bubble formation, that is, bubbles are formed under constant flow conditions.

(2) The bubble grows up spherically.

(3) Bubble motion is not affected by the presence of other bubbles.

(4) The bubble formation consists of two stages, the expansion stage and the detachment stage, as shown in Fig. 1.

(a) Expansion stage: The bubble grows up spherically while it remains at the nozzle as shown in Fig. 1a. This stage ends when the detachment stage begins. 


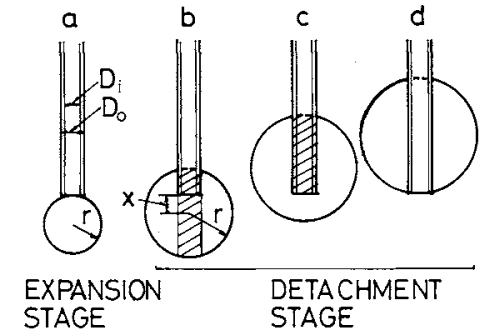

Fig. 1. Schematic diagram of bubble formation.

(b) Detachment stage: This stage begins when the viscous drag force, inertial force, the rate of gas momentum and surface tension acting on the bubble are just balanced by the buoyancy force. The bubble continues to grow while lifting up vertically, but the gas is still fed through the nozzle as shown in Fig. 1b and $c$. This stage terminates when the base of the bubble detaches from the nozzle tip and the bubble separates as shown in Fig. 1d.

1) In the case of wetted nozzle When the nozzle is completely wetted with the liquid, for example, water or organic liquids, the equations which describe the phenomena mentioned above are formulated by using the outer nozzle diameter $D_{o}$ and the inner nozzle diameter $D_{i}$ in the following manner:

In the expansion stage, the constant-flow condition is written as:

$$
Q_{g}=d V_{b 1} / d t=d\left(4 \pi r^{3} / 3\right) / d t=\mathrm{constant}
$$

where initial conditions are $r=D_{i} / 2$ and $d r / d t=$ $Q_{g} / \pi D_{i}^{2}$.

The detachment stage begins, (that is, the expansion stage ends) when the following force balance equation for the bubble lifting up vertically holds:

$$
\begin{aligned}
& \rho_{l} V_{b 2} g=0.5 C_{D} \rho_{l} \pi r^{2}(d r / d t)^{2}+ \\
& \quad d\left(M_{1}^{\prime} d r / d t\right) / d t+4 \rho_{g} Q_{g}^{2} / \pi D_{i}^{2}+\pi D_{i} \sigma
\end{aligned}
$$

Correcting for the presence of the nozzle, the bubble volume $V_{b 2}$ in Eq. (3) is given by volume less the hatched volume shown in Fig. $1 \mathrm{~b}$; that is, $V_{b 2}=$ $4 \pi r^{3} / 3-\pi D_{o}^{2} r / 2 . M_{1}^{\prime}$ in Eq. (3) is the virtual mass for ascending motion of bubble. As the bubble ascends while surrounding the nozzle, it is difficult to obtain the precise virtual mass. In this model $M_{1}^{\prime}$ is assumed to be $0.5 \rho_{l} V_{b 1}$ for a spherical bubble moving parallel to the wall, ${ }^{6)}$ which gives only the order of magnitude of the effect due to the inertia.

In the detachment stage, the constant-flow condition is written as:

$$
Q_{g}=d V_{b 3} / d t=\text { constant }
$$

Correcting for the presence of the nozzle, the bubble volume $V_{b 3}$ is given by the bubble volume less the hatched volume shown in Fig. 1c; that is
$V_{b 3}=4 \pi r^{3} / 3-\pi D_{o}^{2}(r+x) / 4 . x$ is the vertical distance between the bubble center and the nozzle tip. Positive values for $x$ are measured upward from the nozzle tip.

By considering the inertial force, the buoyancy force, viscous drag force, the rate of gas momentum and surface tension on the bubble, the equation of motion for the bubble in the detachment stage is written as follows:

$$
\begin{aligned}
& d\left(M_{2}^{\prime} d x / d t\right) / d t=\rho_{l} V_{b 2} g- \\
& \quad 0.5 C_{D} \rho_{l} \pi r^{2}(d x / d t)^{2}-4 \rho_{g} Q_{g}^{2} / \pi D_{i}^{2}-\pi D_{i} \sigma
\end{aligned}
$$

By the correction for the presence of the nozzle, virtual mass $M_{2}^{\prime}$ is assumed to be $0.5 \rho_{l} V_{b 3}$.

The equations of the detachment stage, Eqs. (4) and (5), can be solved for the initial conditions $r=r_{e f}$, $d r / d t=d r /\left.d t\right|_{e f}, x=-r_{e f}$ and $d x / d t=0$.

The end of the detachment stage is assumed to be when the bubble base detaches from the nozzle tip.

$$
x-r \geqq 0
$$

As the drag coefficient $C_{D}$ in Eqs. (3) and (5), it is appropriate to use the drag coefficient of a bubble sphere rather than a solid sphere, so that $C_{D}-R e$ relation for the bubble sphere was used to calculate bubble formation at an upward-facing orifice in liquids. ${ }^{12)}$

The simultaneous differential equations described above are solved numerically and the final bubble volume $V_{b}$ and the final equivalent spherical diameter. $d_{b}$ in the detachment stage are obtained as follows:

$$
\begin{gathered}
V_{b}=4 \pi r^{3} / 3-\pi D_{o}^{2} r / 2 \\
d_{b}=\left(6 V_{b} / \pi\right)^{1 / 3}
\end{gathered}
$$

2) In the case of nonwetted nozzle When the nozzle is nonwetted with the liquid, for example, a liquid metal, the surface tension terms in Eqs. (3) and (5) are rewritten by using outer nozzle diameter $D_{o}$ instead of inner nozzle diameter $D_{i}$ as follows:

$$
\begin{aligned}
& \rho_{l} V_{b 2} g=0.5 C_{D} \rho_{l} \pi r^{2}(d r / d t)^{2} \\
& \quad+d\left(M_{1}^{\prime} d r / d t\right) / d t+4 \rho_{g} Q_{g}^{2} / \pi D_{i}^{2}+\pi D_{o} \sigma \\
& d\left(M_{2}^{\prime} d x / d t\right) / d t=\rho_{l} V_{b 2} g \\
& \quad-0.5 C_{D} \rho_{l} \pi r^{2}(d x / d t)^{2}-4 \rho_{g} Q_{g}^{2} / \pi D_{i}^{2}-\pi D_{o} \sigma
\end{aligned}
$$

Initial conditions in the expansion stage are rewritten as $r=D_{o} / 2$ and $d r / d t=Q_{g} / \pi D_{o}^{2}$.

The other equations are the same as those in the case of a wetted nozzle, and the final bubble volume and the final equivalent spherical diameter are obtained from Eqs. (7) and (8).

\section{Experimental Apparatus and Procedures}

Figure 2 shows a schematic diagram of the experimental apparatus. The nitrogen gas was fed into a 101 


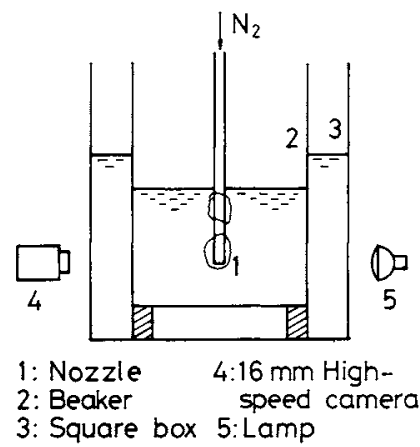

Fig. 2. Schematic diagram of experimental apparatus.

glass beaker of $0.21 \mathrm{~m}$ diameter and bubbles were formed in water through an alumina nozzle of outer and inner diameters $11.8 \times 10^{-3}$ and $7.7 \times 10^{-3} \mathrm{~m}$ respectively. The bubbles formed at the nozzle were photographed by a $16-\mathrm{mm}$ high-speed camera and the films obtained were analysed with a film analyser. To prevent the distortion of bubble shape in the film, the beaker was set in a square box made of acrylic resin filled with water. By assuming that the bubbles were all of the same size, the bubble volume was calculated by dividing gas flow-rate by the bubble formation frequency.

\section{Results and Discussion}

\subsection{Effect of nozzle diameter}

It is considered that the outer and inner nozzle diameters affect the bubble size. Figure 3 shows the relations between bubble size $d_{b}$ and gas flow rate $Q_{g}$ in water for various combinations of outer and inner nozzle diameters obtained from our experimental results and other researchers' experimental results. ${ }^{3,8)}$ The results calculated by this model, shown by curves, fit adequately with the experimental results in the case of water.

It can be seen that the nozzle diameter, especially outer diameter, affects largely the bubble size for small gas flow rates, while it has small effect on the bubble size for large gas flow rates.

In Fig. 3, Eq. (1) by Wraith ${ }^{14)}$ is also shown. It agrees well with experimental data and our model calculation for large gas flow rates.

\subsection{Effect of the physical properties of liquids}

When the nozzle is not wetted with the liquid, it is considered that the effect of inner nozzle diameter on bubble size is negligible and only outer nozzle diameter affects the bubble size. Figure 4 shows the calculated results between bubble diameter $d_{b}$ and the gas flow rate $Q_{g}$ with the physical properties of the liquid as a parameter for the nonwetted nozzle of outer diameter $6.0 \times 10^{-3} \mathrm{~m}$. The curves in the figure correspond to the conditions of the physical properties of liquids as follows: Curve 1, copper melt at $1573 \mathrm{~K}$; Curve 2, hypothetical copper melt whose density is the same as that of water; Curve 3, hypothetical copper melt whose surface tension is the same as that of water; Curve 4, water; Curve 5, Eq. (11), the empirical equation for the upward-facing nozzle in liquid metals. ${ }^{9)}$

$$
d_{b}=0.569\left(Q_{g} D_{o}^{0.5}\right)^{0.289}
$$

Except for high gas flow rates, the effects of both density and surface tension on bubble size are significant, and the bubble size increases with increasing surface tension and with decreasing liquid density.

In the same figure, the experimental results are shown for copper melt at $1573 \mathrm{~K} \quad\left(\rho_{l}=7.80 \times\right.$ $\left.10^{3} \mathrm{~kg} / \mathrm{m}^{3}, \quad \mu_{l}=2.67 \mathrm{mPa} \cdot \mathrm{s}, \quad \sigma=1270 \mathrm{mN} / \mathrm{m}\right)$ with alumina downward nozzle of outer diameter $6.0 \times$ $10^{-3} \mathrm{~m}$ submerged in the column of $5 \times 10^{-2} \mathrm{~m}$ diameter. ${ }^{3)}$ They are nearly equal to the model calculation of Curve 2, but are much larger than that of Curve 1 for copper melt.

The most likely reasons for the discrepancy between the calculated and experimental results are considered to be as follows:

1) As the gas holdup $\varepsilon$ in the liquid metal affects the density of the liquid metal $\rho_{l}$, the apparent density of liquid metal $\rho_{l}^{\prime}$ is written as follows:

$$
\rho_{l}^{\prime}=\rho_{l}(1-\varepsilon)
$$

Gas holdup $\varepsilon$ in the bubble column is given by considering the difference between the rising velocity of a single bubble $u_{b}$ and that of the bubble swarm ${ }^{7)}$ :

$$
\varepsilon=u_{g} /\left(u_{g}+u_{b}\right)
$$

where $u_{g}$ is the superficial gas velocity. The rising velocity of a single bubble in liquid metals is given by the following dimensionless correlation equations corrected by the wall effect $\lambda .{ }^{11}$

$$
\begin{aligned}
& 12 M o^{0.15}<G a^{0.5} M o^{0.23}<7.4: \\
& \operatorname{Re} M o^{0.23} /\left(1-\lambda^{1.5}\right)=2.12\left(G a^{0.5} M o^{0.23}\right)^{0.523} \\
& 7.4<G a^{0.5} M o^{0.23}<23: \\
& R e M o^{0.23} /\left(1-\lambda^{1.5}\right)=1.03\left(G a^{0.5} M o^{0.23}\right)^{0.885} \\
& 23<G a^{0.5} M o^{0.23}: \\
& \operatorname{ReM} o^{0.23} /\left(1-\lambda^{1.5}\right)=0.716 G a^{0.5} M o^{0.23}
\end{aligned}
$$

The bubble diameter in molten metals is estimated from the following equation. ${ }^{10)}$

$$
d_{b}=6.90\left(\sigma / \rho_{l}\right)^{0.5} u_{g}^{0.44}
$$

When the gas flow rate $Q_{g}$ is given, bubble diameter $d_{b}$ is obtained from Eq. (17), $u_{b}$ from Eqs. (14)-(16), $\varepsilon$ from Eq. (13) and $\rho_{l}^{\prime}$ from Eq. (12). Table 1 shows the calculated results for copper melt at $1573 \mathrm{~K}$ for gas flow rates of $1 \times 10^{-5}$ and $1 \times 10^{-4} \mathrm{~m}^{3} / \mathrm{s}$, which correspond to Fleischer's experimental data. ${ }^{3)}$ When the 


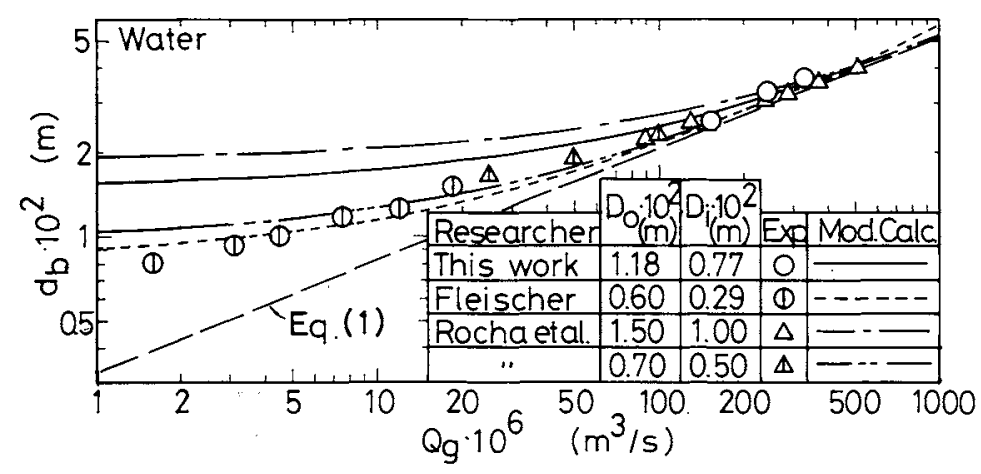

Fig. 3. Relation between bubble diameter and gas flow rate.

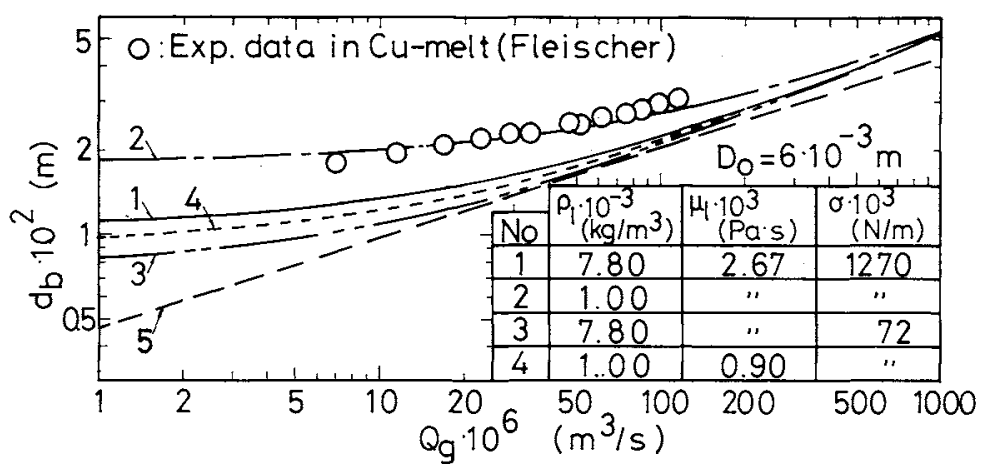

Fig. 4. Effect of the physical properties of liquids on bubble size.

Table 1. Calculation of apparent density of copper melt at $1573 \mathrm{~K}$ (column diameter: $50 \cdot 10^{-3} \mathrm{~m}$ )

\begin{tabular}{rccccc}
\hline $\begin{array}{r}Q_{g} \cdot 10^{6} \\
{\left[\mathrm{~m}^{3} / \mathrm{s}\right]}\end{array}$ & $\begin{array}{c}u_{g} \cdot 10^{2} \\
{[\mathrm{~m} / \mathrm{s}]}\end{array}$ & $\begin{array}{c}d_{b} \cdot 10^{2} \\
{[\mathrm{~m}]}\end{array}$ & $\begin{array}{c}u_{b} \\
{[\mathrm{~m} / \mathrm{s}]}\end{array}$ & $\begin{array}{c}\varepsilon \\
{[-]}\end{array}$ & $\begin{array}{c}\rho_{1}^{\prime} \cdot 10^{3} \\
{\left[\mathrm{~kg} / \mathrm{m}^{3}\right]}\end{array}$ \\
\hline 10 & 0.509 & 0.858 & 0.249 & 0.020 & 7.64 \\
100 & 5.09 & 2.36 & 0.233 & 0.179 & 6.40 \\
\hline
\end{tabular}

gas flow rate increases, the apparent density of copper melt decreases and then the bubble size formed becomes larger. But the effect of gas holdup on bubble size may be neglected in the case of water.

2) As heat transfer between gas bubble and liquid metal is not considered in this model, the bubble size will be predicted to be smaller by this model than by the model considering the heat transfer between bubbles and liquid metals. ${ }^{1)}$

3) Constant flow condition seems to be not actually fulfilled in Fleischer's setup. ${ }^{3)}$

\section{Conclusion}

To predict the size of bubbles formed at a single downward-facing nozzle submerged in liquids or liquid metals, a two-stage bubble formation model was proposed for constant gas flow conditions. The quantitative agreement between results calculated by this model and experimental data for water was fairly good over a wide range of experimental conditions.
On the other hand, the agreement between calculated and experimental results was not so good when copper melt was used as liquid metal. The reasons for this discrepancy were discussed.

It is necessary that more experimental data in liquid metals be accumulated for comparison with the model calculation.

\section{Acknowledgement}

This work was carried out following to the academic exchange program between Technische Universität Berlin and Keio University. The authors wish to express their acknowledgements and thanks to Technische Universität Berlin for support and the fellowship granted to the first author.

$\begin{array}{ll}\text { Nomenclature } \\ C_{D} & =\text { drag coefficient of bubble } \\ D & =\text { column diameter } \\ D_{i} & =\text { inner diameter of nozzle } \\ D_{o} & =\text { outer diameter of nozzle } \\ d_{b} & =\text { equivalent spherical diameter of bubble } \\ G a & =\text { Galilei number, } d_{b}^{3} g \rho_{l}^{2} / \mu_{l}^{2} \\ g & =\text { gravitational acceleration } \\ M & =\text { mass of liquid displaced by bubble } \\ M o & =\text { Morton number, } g \mu_{l}^{4} / \rho_{l} \sigma^{3} \\ M_{s} & =\text { mass of sphere } \\ M_{1}^{\prime}, M_{2}^{\prime} & =\text { virtual mass of bubble } \\ Q_{g} & =\text { gas flow rate } \\ R e & =\text { Reynolds number, } d_{b} u_{b} \rho_{l} / \mu_{l} \\ r & =\text { radius of bubble } \\ t & =\text { bubbling time } \\ u_{b} & =\text { rising velocity of single bubble }\end{array}$

$[-]$ [m] [m] [m] [m] $[-]$ $\left[\mathrm{m} / \mathrm{s}^{2}\right]$ [kg] [-] [kg] $[\mathrm{kg}]$ $\left[\mathrm{m}^{3} / \mathrm{s}\right]$ 


\begin{tabular}{|c|c|c|}
\hline$u_{g}$ & $=$ superficial gas velocity & {$[\mathrm{m} / \mathrm{s}]$} \\
\hline$V_{b}$ & $=$ final bubble volume & {$\left[\mathrm{m}^{3}\right]$} \\
\hline$V_{b 1}, V_{b 2}, V_{b 3}$ & $=$ bubble volume in each stage & {$\left[\mathrm{m}^{3}\right]$} \\
\hline$x$ & $\begin{aligned}= & \text { vertical distance between bubble center and } \\
& \text { nozzle tip }\end{aligned}$ & {$[\mathrm{m}]$} \\
\hline$\varepsilon$ & $=$ gas holdup & {$[-]$} \\
\hline$\lambda$ & $=$ diameter ratio, $d_{b} / D$ & {$[-]$} \\
\hline$\mu$ & $=$ viscosity & {$[\mathrm{Pa} \cdot \mathrm{s}]$} \\
\hline$\rho$ & $=$ density & $\left.\mathrm{kg} / \mathrm{m}^{3}\right]$ \\
\hline$\sigma$ & $=$ surface tension & {$[\mathrm{N} / \mathrm{m}]$} \\
\hline
\end{tabular}

〈Subscripts〉

$$
\begin{array}{ll}
\text { ef } & =\text { final value of expansion stage } \\
g & =\text { gas } \\
l & =\text { liquid }
\end{array}
$$

\section{Literature Cited}

1) Ashman, D. W., J. W. McKelliget and J. K. Brimacombe: Can. Met. Quart., 20, 387 (1981).

2) Davidson, L. and E. H. Amick, Jr.: AIChE J., 2, 337 (1956).
3) Fleischer, G.: Dr. Thesis, TU Berlin, F.R.G. (1983).

4) Irons, G. A. and R. I. L. Guthrie: Met. Trans. B., 9B, 101 (1978).

5) Mersmann, A.: VDI Forschungsheft, 491, 1 (1962).

6) Milne-Thomson, L. M.: "Theoretical Hydrodynamics," 5th ed., Macmillan, p. 490 (1968).

7) Nicklin, D. J.: Chem, Eng. Sci., 17, 693 (1962).

8) Rocha, F. A. N. and J. R. F. Guedes de Garvalho: Chem. Eng. Res. Des., 62, 303 (1984).

9) Sano, M. and K. Mori: Tetsu to Hagane, 60, 348 (1974).

10) Sano, M., K. Mori and Y. Fujita: Tetsu to Hagane, 65, 1140 (1979).

11) Tsuge, H. and S. Hibino: Kagaku Kogaku Ronbunshu, 3, 95 (1977).

12) Tsuge, H. and S. Hibino: J. Chem. Eng. Japan, 11, 173 (1978).

13) Tsuge, H. and S. Hibino: Chem. Eng. Commun., 22, 63 (1983).

14) Wraith, A. E.: Proc. Int. Proceedings of Symp. of Inst. Mining and Metallurgy, p. 303 (1972).

(A part of this paper was presented at 50th Annual Meeting of the Society of Chemical Engineers, Japan, at Yokohama, March 1985.)

\title{
GAS HOLDUP AND PRESSURE DROP IN THREE-PHASE HORIZONTAL FLOWS OF GAS-LIQUID-FINE SOLID PARTICLES SYSTEM
}

\author{
YASUO HATATE, HIROSHI NOMURA, TAKANORI FUJITA, \\ SHUICHI TAJIRI AND ATSUSHI IKARI \\ Department of Chemical Engineering, Faculty of Engineering, \\ Kagoshima University, Kagoshima 890
}

Key Words: Multiphase Flow, Gas Holdup, Pressure Drop, Horizontal Flow, Slurry

\begin{abstract}
Gas holdups and pressure drops of gas-liquid-solid cocurrent three-phase flow containing fine solid particles of 30, 60 and $100 \mu \mathrm{m}$ average size were measured in horizontal tubes and the following results were obtained.

(1) Gas holdups at the conditions of homogeneous slurry flow are the same as those of gas-liquid two-phase flow. However, the heterogeneity of slurry flow reduces the gas holdup. Considering these aspects, a gas holdup correlation of gas-liquid-solid three-phase horizontal flow is proposed to correlate the data over a wide range of operating conditions.

(2) Pressure drops of gas-liquid-solid three-phase flow in horizontal tubes are more considerably influenced by solid intermixing than those in vertical tubes. A correlation to describe the pressure drop of gas-liquid-solid threephase horizontal flow is proposed.
\end{abstract}

\section{Introduction}

In the design of wet desulfurization and coal liquefaction plants, it is important to specify the hydrodynamics of gas-liquid-fine solid particles threephase flow systems. A few published work $\mathrm{s}^{5,6)}$ on gas-

Received December 16, 1985. Correspondence concerning this article should be addressed to Y. Hatate. H. Nomura is now at Tokuyama Soda Co., Ltd. T. Fujita is now at Daikin Co., Ltd liquid-solid flows conceive problems in the applicability to such plant systems containing fine solid particles, because solid particles above $100 \mu \mathrm{m}$ in size were used in the literature. The hydrodynamic information from gas-liquid two-phase flows would better have been used to predict the hydrodynamics of such plant systems. To reduce that serious problem, gas holdups and pressure drops of gas-liquid-fine solid particles flows were measured in vertical upflow and 